\title{
Sisters: The Personal Story of an Irish Feminist
}

\section{Nathalie Sebbane}

\section{(2) OpenEdition}

\section{Journals}

\section{Édition électronique}

URL : http://journals.openedition.org/etudesirlandaises/1915

DOI : 10.4000/etudesirlandaises. 1915

ISSN : 2259-8863

\section{Éditeur}

Presses universitaires de Caen

\section{Édition imprimée}

Date de publication : 30 juin 2010

Pagination : 188-190

ISSN : 0183-973X

\section{Référence électronique}

Nathalie Sebbane, "Sisters: The Personal Story of an Irish Feminist », Etudes irlandaises [En ligne], 35-1 | 2010, mis en ligne le 30 septembre 2010, consulté le 21 septembre 2020. URL : http://

journals.openedition.org/etudesirlandaises/1915; DOI : https://doi.org/10.4000/etudesirlandaises. 1915

Ce document a été généré automatiquement le 21 septembre 2020.

\section{(c) (i) (2)(2)}

Études irlandaises est mise à disposition selon les termes de la Licence Creative Commons Attribution - Pas d'Utilisation Commerciale - Partage dans les Mêmes Conditions 4.0 International. 


\title{
Sisters: The Personal Story of an Irish Feminist
}

\author{
Nathalie Sebbane
}

\section{RÉFÉRENCE}

June Levine, Sisters: The Personal Story of an Irish Feminist, Dublin, Attic Press, 2009, 352 p., ISBN 978-1-85594-211-0

1 June Levine naît en 1932 à Dublin, d'une mère catholique et d'un père juif. Elle hérite d'emblée d'une double culture fortement ancrée dans des traditions patriarcales. Après avoir épousé un jeune étudiant en médecine, elle quitte Dublin pour le Canada où elle s'installe et fonde une famille. Lentement et imperceptiblement, elle sombre dans une profonde dépression. A cette époque, Betty Friedan publie The Feminine Mystique. Elle y décrit les souffrances endurées par des femmes intelligentes et ambitieuses, enfermées dans la cage dorée du mariage. June lit ce livre sans, de son propre aveu, forcément bien en comprendre les enjeux. Mais elle se rend néanmoins compte que sa vie ne peut se limiter à être une bonne épouse et une bonne mère. Après une hospitalisation, au cours de laquelle elle subit électrochocs et traitements à l'insuline, elle rentre en Irlande avec ses trois enfants mais sans son mari.

Elle se met, dès lors, en quête d'une autre vie et entreprend une carrière de journaliste. Elle commence par écrire pour des magazines féminins et découvre que la femme, dans les années 1960, n'est perçue que comme un objet superficiel et docile. Sa rencontre avec d'autres femmes, personnages clés du mouvement féministe irlandais - Mary Kenny, l'exubérante, Mary Maher, la journaliste, Nell McCafferty, l'infatigable militante, Mairin de Burca, membre de Sinn Fein et Nuala Fennell, pour ne citer qu'elles - journalistes pour la plupart, la conduit peu à peu à participer à des réunions au dessus du restaurant Gaj, à Baggot Street, où s'ébauche une véritable prise de conscience du féminisme et des enjeux afférents. Ainsi, dans les années 1970-71, elle devient l'un des membres fondateurs du Mouvement de Libération de la Femme, dans une Irlande 
solidement installée dans un schéma patriarcal qui nie moralement et légalement aux femmes tout droit sur leur vie, leur corps, leur travail et leur liberté. June trouve sa place parmi ses femmes et trouve les raisons du profond malaise qui l'a conduit à la dépression. "Nous vivions en territoire occupé », dit-elle. "Le monde entier, pour les femmes, était un territoire occupé. Nous avions juste le droit de partager ce qu'ils s'étaient approprié ».

3 Sisters est considéré par beaucoup comme un texte fondateur de l'histoire du mouvement féministe irlandais. Publié en 1982, alors que Levine était installée dans une carrière de journaliste et qu'elle était également collaboratrice de Gay Byrne pour l'émission The Late Late Show, l'ouvrage est à la fois une contribution importante à l'histoire sociale de l'Irlande mais également, et peut-être essentiellement, un parcours personnel et initiatique, la quête d'une femme pour son émancipation. Le personnel et le politique sont intimement liés et jalonnent le parcours de cette femme engagée, qui ose révéler les contradictions qui l'ont conduite sur le chemin du féministe. L'idéal n'est pas dans le combat ni dans ses formes mais dans la cause qui l'anime.

Dans Sisters, June Levine brosse les portraits, souvent peu complaisants, des femmes qu'elle a côtoyées mais elle n'hésite pas non plus à relayer les impressions de ses contemporaines, de ses "sœurs", sur sa propre personnalité. Elle est, tour à tour, décrite comme la femme au foyer idéale, une cuisinière hors pair, mais également une femme à hommes, coquette, sensuelle, militante, déterminée. Ces différentes vignettes sont autant de fenêtres sur les multiples facettes du féminisme. Chaque femme qui a épousé la cause l'a fait pour des raisons différentes, ses raisons propres, liées à son parcours personnel. Pour autant, toutes, main dans la main, sont se battues côte à côte, pour que leurs sœurs parviennent à se libérer du joug d'une oppression ancestrale.

La lecture de Sisters est infiniment plaisante. Levine écrit dans une langue claire, alerte, lucide. Elle parcourt plusieurs décennies de l'histoire de son pays avec humour et réalisme. Elle dénonce l'hypocrisie de la société irlandaise face à des enjeux comme la contraception et l'avortement. Et surtout, elle revient aux racines du mouvement féministe, débarrassé de ses clichés.

6 Quiconque s'intéresse à l'histoire des femmes et à l'histoire de l'Irlande, mesurera la contribution de cet ouvrage. Il écrit une page laissée blanche pendant bien trop longtemps et donne une voix à des femmes dont l'engagement politique est, depuis trop longtemps, passé sous silence. 